\title{
KEANEKARAGAMAN DAN KELIMPAHAN KARANG JENIS FAMILI FUNGIIDAE DI PERAIRAN DESA ATOWATU KABUPATEN KONAWE
}

\section{Coral Diversity and Abundance of Family Fungiidae in Atowatu Seawaters, Konawe Regency}

\author{
Sahril Syam ${ }^{1}$, Baru Sadarun ${ }^{2}$, dan Ratna Diyah Palupi ${ }^{3}$ \\ ${ }^{1}$ Mahasiswa Jurusan Ilmu Kelautan, \\ Fakultas Perikanan dan Ilmu Kelautan, Universitas Halu Oleo. \\ Jl. H.E.A Mokodompit Kampus Hijau Bumi Tridharma Anduonohu Kendari 93232, Telp/Fax: (0401) 3193782 \\ ${ }^{2}$ Surel: sadarunbaru@gmail.com \\ ${ }^{3}$ Surel: pratna97@yahoo.com
}

\begin{abstract}
Abstrak
Karang famili Fungiidae merupakan karang yang masuk ordo Scleractinia yang hidup soliter dan bebas tidak melekat pada substrat dasar perairan. Penelitian ini bertujuan untuk mengetahui keanekaragaman dan kelimpahan jenis karang famili Fungiidae di perairan Desa Atowatu. Pengambilan data penelitian dilaksanakan pada bulan Januari 2019. Stasiun pengambilan data terdiri dari 3 stasiun penelitian. Penentuan stasiun menggunakan metode purposive sampling yaitu dengan memilih stasiun berdasarkan keberadaan karang famili Fungiidae di daerah reef flat dan reef slope. Pengambilan data kelimpahan karang Fungiidae menggunakan metode Belt transect, dengan panjang transect 70 x $2 \mathrm{~m}$. Hasil penelitian keanekaragaman famili Fungiidae di perairan Desa Atowatu terdiri dari 8 genus, 22 spesies, dan 1300 individu dengan genus fungia yang medominasi hasil penelitian. Kelimpahan yang didapatkan pada daerah reef flat tertinggi pada stasiun I (2.39 individu/ $\left.\mathrm{m}^{2}\right)$ kemudian disusul stasiun III $\left(2.25\right.$ individu $\left./ \mathrm{m}^{2}\right)$ dan yang terendah stasiun II (1.83 individu $\left./ \mathrm{m}^{2}\right)$. Daerah reef slope tertinggi didapatkan pada stasiun II (1.70 individu/ $\left.\mathrm{m}^{2}\right)$ kemudian disusul stasiun I (1.67 individu $\left./ \mathrm{m}^{2}\right)$ dan terendah stasiun III (1.00 individu $\left./ \mathrm{m}^{2}\right)$. Rata-rata kelimpahan famili Fungiidae sebesar 2,16 individu $/ \mathrm{m}^{2}$ pada daerah reef flat dan reef slope sebesar 1,45 individu $/ \mathrm{m}^{2}$. Keanekaragaman dan kelimpahan famili Fungiidae dominan di zona reef flat dibandingkan reef slope.
\end{abstract}

Kata kunci : Keanekaragaman, Kelimpahan, Karang Fungiidae, Reefflat, Reef slope

\section{Abstract}

The Fungiidae corals are an order of Scleractinia which are a solitary free-living corals and sessile organisms in seabottom substrate. This study aimed to determine the diversity and abundance of Fungiidae coral in Atowatu Village. Purposive sampling method was used to determine3 sampling sites based on the presence of family Fungiidae coral in reef flat and reef slope area. Belt transect method with length 70x2 m was applied to collect data. Results showed that the diversity of the Fungiidae family in location consisted of 8 genera, 22 species, and 1,300 individuals from Fungia genus. In reef flat area, the highest abundance found at station I (2.39 individuals $\left./ \mathrm{m}^{2}\right)$ followed by station III $(2.25$ individuals $\left./ \mathrm{m}^{2}\right)$ while the lowest found at station II $\quad\left(1.83\right.$ individuals $\left./ \mathrm{m}^{2}\right)$. In reef slope area, the highest abundance found at station II $\left(1.70\right.$ individuals $\left./ \mathrm{m}^{2}\right)$ then followed by station I $\left(1.67\right.$ individuals $\left./ \mathrm{m}^{2}\right)$ while the lowest found at station III (1.00 individuals $/ \mathrm{m}^{2}$ ). The average abundance achieved 2.16 individuals $/ \mathrm{m}^{2}$ in reef flat area and 1.45 individuals $/ \mathrm{m}^{2}$ in reef slope area. The diversity and abundance of Fungiidae family was more dominant in the reef flat zone compared to the reef slope.

Keywords: Diversity, Abundance, Fungiidae corals, Reef flat, Reef slope

\section{Pendahuluan}

Terumbu karang sebagai ekosistem khas perairan tropis merupakan habitat berbagai biota laut untuk tumbuh dan berkembang biak. Namun terumbu karang saat ini telah mengalami kerusakan yang disebabkan oleh berbagai faktor seperti pengasaman laut, naiknya temperatur akibat perubahan iklim, penangkapan ikan berlebihan, dan polusi.

Karang famili Fungiidae merupakan salah satu spesies karang yang hidup soliter (free-living) dan mampu hidup di berbagai macam substrat. Sebagian besar spesies ini dapat ditemukan pada lereng terumbu yang memiliki substrat patahan karang (Hoeksema, 2012). Fungsi penelitian ini untuk mengetahui kelimpahan dan keanekaragaman karang famili fungidae.

Tujuan penelitian ini adalah untuk mengetahui keanekaragaman dan kelimpahan jenis karang famili Fungiidae berdasarkan zonasi terumbu karang reef flat dan reef 
slope di perairan Desa Atowatu, Kecamatan Soropia, Kabupaten Konawe. Manfaat dari penelitian ini adalah sebagai bahan informasi yang penting dalam mengetahui kelimpahan dan keanekaragaman jenis karang famili Fungiidae dan dapat dikelola secara berkelanjutan.

\section{Bahan dan Metode}

Penelitian dilaksanakan pada bulan Januari 2019. Bertempat di perairan Desa Atowatu, Kecamatan Soropia, Kabupaten Konawe, Provinsi Sulawesi Tenggara. Desa ini terletak di wilayah pesisir dan di tumbui ekosistem Terumbu Karang. Setiap stasiun ditentukan koordinatnya dengan menggunakan Global Positioning System (GPS).

Tahap awal dalam penentuan stasiun adalah melakukan survei pendahuluan. Survei pendahuluan bertujuan untuk memilih titik stasiun yang dianggap sesuai agar pengambilan sampel dapat mewakili atau menggambarkan kondisi populasi karang famili Fungiidae di lapangan. Survei awal dilakukan dengan cara menyelam di sekitar area terumbu karang dengan menggunakan metode purposive sampling. Penentuan titik penelitian sebanyak 3 (tiga) stasiun yang diambil keterwakilan zonasi terumbu karang yaitu area rataan terumbu (reef flat), dan area lereng terumbu (reef slope).

Setiap stasiun ditentukan koordinatnya dengan menggunakan Global Positioning System (GPS). Letak stasiun penelitian, stasiun I berada pada titik koordinat $3^{\circ} 52^{\prime} 51.58^{\prime \prime}$ LS dan $122^{\circ} 37^{\prime} 36.52^{\prime \prime}$ BT. Kondisi stasiun I memiliki karang hidup dengan bentuk pertumbuhan mushroom, acropora branching, dan coral branching. Karang hidup yang didominasi stasiun ini adalah coral mushroom. Substrat dasar di stasiun ini didominasi substrat patahan karang, yang berada pada daerah reef flat dan reef slope didominasi karang mati ditumbuhi alga. Stasiun II berada pada koordinat $3^{\circ} 52^{\prime} 55.07^{\prime \prime}$ LS dan $122^{\circ} 36^{\prime} 54.15^{\prime \prime}$ BT. Kondisi stasiun II didominasi karang hidup dengan bentuk pertumbuhan coral mushroom. coral massive, dan acropora branching. Karang hidup yang didominasi stasiun ini adalah acropora branching. Substrat dasar di stasiun ini didominasi substrat hard coral dan karang mati yang berada di daerah reef flat dan reef slope dominan karang mati yang ditumbuhi alga. Stasiun III berada di koordinat $3^{\circ} 53^{\prime} 1.03^{\prime \prime}$ LS dan $122^{\circ} 366^{\prime} 6.64^{\prime \prime}$ BT. Kondisi stasiun I memiliki karang hidup dengan bentuk pertumbuhan coral mushroom dan coral branching. Karang hidup yang didominasi stasiun ini adalah coral mushroom. Substrat dasar di stasiun ini didominasi substrat patahan karang, yang berada pada daerah reef flat dan reef slope didominasi substrat karang mati ditumbuhi alga dan pasir berlumpur.

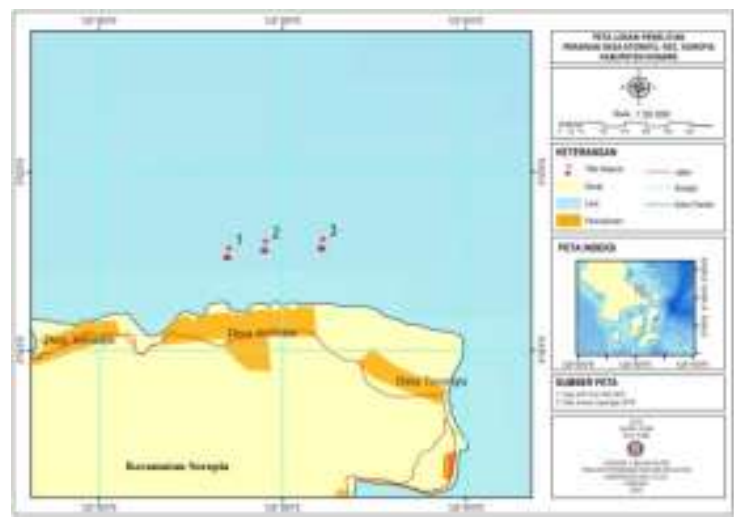

Gambar 1. Peta Lokasi Penelitian Perairan Desa Atowatu

Pengambilan data karang famili Fungiidae menggunakan metode transek sabuk atau belt transect (Hill and Wilkinson, 2004). Transek sabuk dibuat dengan panduan roll meter (transek garis) yang dibentangkan sejajar dengan garis pantai sepanjang $70 \mathrm{~m}$. Pengambilan data karang dilakukan dalam luasan $70 \times 2 \mathrm{~m}\left(140 \mathrm{~m}^{2}\right)$. Setiap stasiun dilakukan dua kali pengulangan pengambilan data. Pengambilan data dilakukan dengan menghitung jumlah individu/koloni karang famili Fungiidae dan mencatat jenisnya. Kamera bawah air digunakan untuk membantu menganalisis jenis karang yang belum sempat teridentifikasi di lapangan.

\section{Analisis Data}

Kelimpahan adalah jumlah individu per satuan luas atau per satuan volume Kelimpahan dihitung menurut Brower dan Zar (1997) menggunakan rumus:

$\boldsymbol{N}=\frac{\sum \mathrm{n}}{\mathrm{A}}$

Dimana:

$\mathrm{N}=$ Kelimpahan Individu ( individu $/ \mathrm{m}^{2}$ )

$\sum \mathrm{n}=$ Jumlah individu yang diperoleh tiap stasiun

$\mathrm{A}=$ Luas daerah pengamatan $\left(\mathrm{m}^{2)}\right.$

Cara mengetahui

hasil

keanekaragaman dengan cara didata secara taksonomi selanjutnya dianalisis dan disajikan dalam bentuk grafik dan tabel. 


\section{Hasil dan Pembahasaan}

Berdasarkan pengambilan data dari tiga stasiun, di perairan Desa Atowatu kelimpahan karang famili Fungiidae bisa dilihat pada Tabel 1. Bahwa tiap stasiun penelitian dengan kelimpahan yang didapatkan mencapai 1.002.39 individu $/ \mathrm{m}^{2}$, dengan rata-rata kelimpahan yaitu pada daerah rataan terumbu karang (reef flat) sebesar 2.16 individu $/ \mathrm{m}^{2}$ dan pada daerah lereng terumbu (reef slope) mencapai 1.45 individu $/ \mathrm{m}^{2}$.

Hasil penelitian untuk stasiun I dan III pada daerah rataan terumbu reef flat dengan kedalaman $2 \mathrm{~m}$ berada pada substrat patahan karang (rubble), kelimpahan yang didapatkan untuk stasiun I 2.39 individu $/ \mathrm{m}^{2}$ sedangkan pada stasiun III didapatkan 2.25 individu $/ \mathrm{m}^{2}$ hal ini menandakan bahwa stasiun I dan III hampir sama dikarenakan memiliki substrat yaitu patahan karang (rubble). Hal ini sesuai pernyataan Mampuk dkk., (2013) dimana rubble atau patahan karang merupakan substrat yang cocok untuk karang famili Fungiidae.

Berdasarkan hasil penelitian stasiun II kelimpahan yang didapatkan yaitu 1.83 individu $/ \mathrm{m}^{2}$, yang memilki substrat hard coral dan karang mati yang telah ditumbuhi alga. Hal ini dibandingkan dengan stasiun I dan III itu jauh berbeda dikarenakan karang jenis famili Fungiidae lebih menyukai hidup pada substrat yang berpasir dan patahan karang. Hal ini sesuai peryataan Kramarsky dan Loya (1994) dimana rendahnya kelimpahan karang jenis famili Fungiidae diakibatkan berada pada substrat hard coral dan karang mati yang ditumbuhi alga. Hasil ini masih relatif lebih tinggi jika dibandingkan dengan kelimpahan karang jamur di perairan Pulau Gangga Sulawesi Utara yaitu berkisar 0,13-1,22 individu/ $\mathrm{m}^{2}$ menurut (Hermanto, 2014).

Hasil penelitian untuk stasiun I dan II pada daerah reef slope dengan kedalaman $6 \mathrm{~m}$ berada pada substrat karang mati yang ditumbuhi oleh alga, kelimpahan yang didapatkan untuk stasiun I 1.67 individu $/ \mathrm{m}^{2}$ sedangkan pada stasiun II didapatkan 1.70 individu $/ \mathrm{m}^{2}$ hal ini menandakan bahwa stasiun I dan II hampir sama dikarenakan memiliki substrat karang mati yang ditumbuhi alga, dan berpasir dikategorikan sangat rendah kelimpahannya dibandingkan dengan kelimpahan karang pada daerah reefflat.

Hal ini sesuai pernyataan Noosstrom (2006) dimana kondisi rataan terumbu yang tidak terlalu curam dan substrat dasar yang didominasi oleh patahan karang yang baik untuk penempelan larva karang jamur. Dibandingkan dengan stasiun III 1.00 individu $/ \mathrm{m}^{2}$ memang sangat minim kelimpahannya, diakibatkan pada daerah stasiun ini memilki substrat karang mati hampir semua ditumbui oleh alga dan pasir berlumpur hal ini sesuai pernyataan Gofredo dan Furman (2000), beberapa karang jamur masih bisa ditemukan pada lokasi yang memiliki substrat berlumpur dan berpasir, akan tetapi kelimpahannya lebih rendah jika dibandingkan dengan lokasi yang didominasi substrat patahan karang.

Kelimpahan jenis karang famili Fungiidae berdasarkan zonasi karang dari tiga stasiun, reef flat dan reef slope yang memilki kelimpahan tertinggi yaitu reef flat karena memiliki substrat yang sangat mendukung untuk pertumbuhan karang jamur yaitu substrat patahan karang dan berpasir dapat dilihat pada Gambar 11, hal ini sesuai pernyataan Suharsono (2010), dimana reef flat paling banyak ditemukan karena keberadaan substrat yang sangat mendukung yaitu patahan karang (rubble). Beda dengan reef slope memilki substrat karang mati dan ditumbuhi alga sehingga kelimpahannya sangat kurang menurut Hoeksema (1989) mengungkapkan bahwa pada daerah terumbu karang khususnya karang famili Fungiidae dengan topografi reef slope akan jarang ditemukan karang jamur dengan jumlah yang melimpah.

Tabel 1. Kelimpahan Jenis Karang Famili Fungiidae di Perairan Desa Atowatu

\begin{tabular}{ccc}
\hline \multirow{2}{*}{ Stasiun } & \multicolumn{2}{c}{ Kelimpahan $\left(\right.$ Individu $\left./ \mathbf{m}^{2}\right)$} \\
\cline { 2 - 3 } & Rataan $($ reefflat $)$ & Lereng $($ reef slope $)$ \\
I & 2.39 & 1.67 \\
II & 1.83 & 1.70 \\
III & 2.25 & 1.00 \\
\hline Rata-rata & 2.16 & 1.45 \\
\hline
\end{tabular}


Tabel 2. Keanekaragaman Jenis dan jumlah individu Karang Famili Fungiidae di Perairan Desa Atowatu

\begin{tabular}{|c|c|c|c|c|c|c|c|c|}
\hline \multirow{2}{*}{ No. } & \multirow{2}{*}{ Genus } & \multirow{2}{*}{ Spesies } & \multicolumn{2}{|c|}{ Stasiun I } & \multicolumn{2}{|c|}{ Stasiun II } & \multicolumn{2}{|c|}{ Stasiun III } \\
\hline & & & $\mathrm{F}$ & $\mathrm{S}$ & $\mathrm{F}$ & $\mathrm{S}$ & $\mathrm{F}$ & $\mathrm{S}$ \\
\hline \multirow[t]{3}{*}{1} & Ctenactis & Ctenactis albitentaculata & 3 & & & & & \\
\hline & & Ctenactis echinata & 25 & 13 & 12 & 12 & 18 & 16 \\
\hline & & Ctenactis crassa & 22 & 18 & 3 & 10 & 5 & 13 \\
\hline \multirow[t]{5}{*}{2} & Cylcoseris & Cylcoseris costulata & 25 & 16 & 12 & 13 & 16 & 15 \\
\hline & & Cylcoseris patelliformis & 32 & 20 & 22 & 23 & 25 & 23 \\
\hline & & Cylcoseris Somervillei & 26 & 12 & 14 & 2 & 3 & 2 \\
\hline & & Cylcoseris vaugani & 25 & 19 & 6 & 9 & 5 & 9 \\
\hline & & Cylcoseris hexagonalis & 18 & 13 & 15 & 12 & 14 & 11 \\
\hline \multirow[t]{7}{*}{3.} & Fungia & Fungia concinna & 42 & 29 & 15 & 16 & 19 & 15 \\
\hline & & Fungia fungites & 14 & 9 & 25 & 12 & 25 & 23 \\
\hline & & Fungia horrida & 11 & 3 & 12 & 13 & 11 & 4 \\
\hline & & Fungia mollucensis & 16 & 25 & 4 & 9 & 5 & 3 \\
\hline & & Fungia paumotensis & 29 & 12 & 25 & 14 & 15 & 18 \\
\hline & & Fungia scabra & 15 & 13 & 11 & 8 & 9 & 14 \\
\hline & & Fungia scutaria & 16 & 2 & 5 & 9 & 5 & 6 \\
\hline 4. & Halomitra & Halomitra pileus & 4 & 4 & 6 & 5 & 2 & 3 \\
\hline \multirow[t]{2}{*}{5.} & Herpolitha & Herpolitha limax & 6 & 3 & 3 & 6 & 5 & 2 \\
\hline & & Herpolitha weberi & 5 & & 6 & 4 & 2 & 3 \\
\hline 6. & Podabocia & Podabocia crustacea & 1 & & & & & \\
\hline \multirow[t]{2}{*}{7.} & Polyphyllia & Polyphyllia talpina & & & 2 & & & \\
\hline & & Sandalolitha dentata & & 4 & & & 2 & \\
\hline \multirow[t]{2}{*}{8.} & Sandalolitha & Sandalolitha robusta & 2 & & 2 & 1 & & \\
\hline & $\begin{array}{l}\text { Total } \\
\text { individu: }\end{array}$ & 1300 individu & 334 & 221 & 201 & 178 & 186 & 180 \\
\hline
\end{tabular}

Keterangan : F (flat) S (slope)

Hasil kelimpahan yang didapatkan dari tiga stasiun berdasarkan data oseanografi pada reef flat dan reef slope dari tiga stasiun dengan membandingkan kelimpahan masing-masing stasiun masih terbilang stabil karena data suhu yang didapatkan sangat mendukung untuk kelimpahan karang famili Fungiidae. Hal ini sesuai pernyataan Nyabakken (1992), dijelaskan bahwa ada beberapa faktor fisik dan kimia yang sangat berpengaruh terhadap kelimpahan karang dan pertumbuhan karang yaitu faktor kecerahan,temperatur $\left(25-29^{\circ} \mathrm{C}\right)$, salinitas (32-35 ppt), sedimentasi, dan arus. Menurut pernyataan Sukarno dkk., (1981) menyatakan bahwa kehadiran karang jamur pada suatu perairan dipengaruhi oleh faktor fisik perairan seperti salinitas, suhu, kecerahan perairan maupun beberapa parameter kimia air laut seperti fosfat dan nitrat.

Hasil foto yang kemudian diidentifikasi, jenis karang famili Fungiidae tertera pada Tabel 2 dimana di temukan 8 Genus, 22 Spesies dan 1300 individu. Kemudian berdasarkan persentase jenis karang famili
Fungiidae bisa dilihat pada Gambar 2, berdasarkan gambar tersebut Genus Fungia, Cylcoseris, dan Herpolitha saja yang dominan berada pada tiga stasiun tersebut. Berdasarkan data yang diperoleh dari masing-masing stasiun pengamatan, ditemukan 1300 individu karang famili Fungiidae terdiri dari 22 spesies yang termasuk dalam 8 genus. Keanekaragaman karang famili Fungiidae di perairan Desa Atowatu tergolong sedikit bila dibandingkan dengan jumlah jenis yang ada di dunia dari 56 spesies dan 13 Genera (Veron, 2000).

Berdasarkan hasil persentase jenis karang famili Fungiidae yang dominan didapatakan ada tiga genus yaitu Fungia 33\%, Genus Cylcoseris 24\%, dan Genus Herpolitha $14 \%$. substrat patahan karang dan daerah rataan terumbu (reef flat) sehingga tiga genus ini dominan pada perairan Desa Atowatu. Hal ini sesuai penyataan Hoeksema (2013) dimana kondisi habitat dan ekologis pada suatu lokasi merupakan salah satu faktor yang mempengaruhi keanekaragaman serta kepadatan karang jamur. 


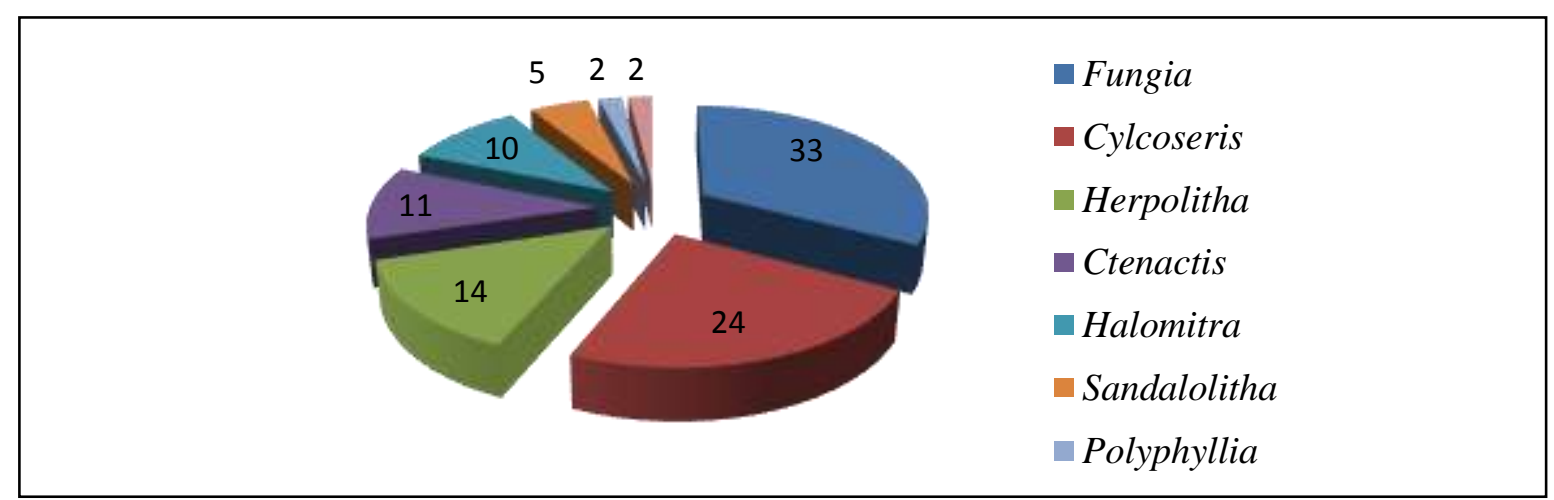

Gambar 2. Persentase Jumlah Genus dan Spesies Famili Fungiidae

\begin{abstract}
Keanekaragaman karang famili Fungiidae diperairan Desa Atowatu berdasarkan persentase, yang lebih banyak ditemukan genus Fungia 33\% karena berada pada substrat yang sangat cocok yaitu patahan karang dan berpasir. Hal ini sesuai pernyataan Manuputty (1990) bahwa karang jenis Fungia sangat cocok berada pada substrat patahan karang. Serta didukung dengan faktor fisika dan kimia dimana suhu $31-32^{\circ} \mathrm{C}$, salinitas 31-32 Ppt, kecerahan $100 \%$, pH 7-8 dan kecepatan 0.10-1.12 m/det masih teribilang stabil. Hal ini sesuai dengan pernyataan Sukarno., et al (1981) kondisi perairan yang jernih dan mempunyai salinitas yang berkisar antara 30-31 Ppt dan temperatur air laut yang berkisar antara $28,50-29^{\circ} \mathrm{C}$ sangat mendukung untuk keberagaman karang jamur.
\end{abstract}

Kemudian disusul genus Cycloseris $24 \%$, dimana genus ini tidak jauh berbeda dengan genus Fungia dan banyak sekali ditemukan pada substrat patahan karang dan rataan terumbu (reef flat) dan bisa beradaptasi dengan berbagai macam kondisi. Hal ini sesuai dengan pernyataan Suharsono (2010) dimana genus Cycloseris merupakan karang jamur yang dapat beradaptasi dengan berbagai kondisi substrat dasar perairan. Serta didukung dengan faktor fisika dan kimia dapat dilihat pada (Gambar 4-6) masih terbilang stabil. Hal ini sesuai dengan pernyataan Sukarno., et al (1981) kondisi perairan yang jernih dan mempunyai salinitas yang berkisar antara 30-31 ppt dan temperatur air laut yang berkisar antara 28$29^{\circ} \mathrm{C}$ sangat mendukung untuk keberagaman karang jamur.

Dibandingkan keanekaragaman genus Herpolitha $14 \%$ yang berada pada lereng terumbu (reef slope) dan genus ini berada pada substrat karang mati yang ditumbuhi alga, serta berlumpur sehingga keanekaragamannya sangat rendah. Hal ini sesuai pernyataan Norsstrom (2006), bahwa jika habitat karang genus Herpolitha tidak cukup baik disebabkan karena substrat karang mati yang ditumbuhi algae dan berlumpur. Berdasarkan data oseanografi sangat mendukung dimana suhu $31-32^{\circ} \mathrm{C}$, salinitas 31-32 ppt, kecerahan 100\%, pH 7-8 dan kecepatan 0.10-1.12 $\mathrm{m} / \mathrm{det}$ masih terbilang stabil. Hal ini sesuai pernyataan Sukarno dkk., (1981) kondisi suhu dan salinitas perairan mendukung pola sebaran karang batu yang biasanya hidup pada suhu antara $25-30^{\circ} \mathrm{C}$ dengan salinitas berkisar dari 27-40 Ppt. Sukarno et al. (1981) yang menyebutkan toleransi salinitas untuk pertumbuhan karang jamur umumnya berkisar antara 25-40 ppt. Nilai $\mathrm{pH}$ berkisar antara 7,96-8,17 pH. Menurut Nyabakken (1992), dijelaskan bahwa ada beberapa faktor fisik dan kimia yang membatasi distribusi dan pertumbuhan karang yaitu faktor kecerahan, temperatur $\left(31-35^{\circ} \mathrm{C}\right)$, salinitas 32-35 ppt, sedimentasi, dan arus

\section{Simpulan}

Berdasarkan hasil penelitian dan pembahasan, dapat disimpulakan bahwa Keanekaragaman karang famili Fungiidae di lokasi penelitian terdiri dari 8 genus, 22 spesies dan 1300 individu. Kelimpahan karang famili Fungiidae tertinggi pada daerah reef flat stasiun I (2.39 individu $/ \mathrm{m}^{2}$ ) kemudian disusul stasiun III $\quad(2.25$ individu $\left./ \mathrm{m}^{2}\right)$ dan terendah di stasiun II (1.83 individu $/ \mathrm{m}^{2}$ ). Kelimpahan karang famili Fungiidae tertinggi berada pada daerah reef slope stasiun II sebesar 1.70 individu $/ \mathrm{m}^{2}$ kemudian disusul stasiun I 1.67 individu $/ \mathrm{m}^{2}$ dan terendah stasiun III 1.00 individu $/ \mathrm{m}^{2}$. 


\section{Daftar Pustaka}

Barnes R.S.K dan Hughes RN. 1999. An Introduction to Marine Ecology (Third Edition). Blackwell Publishing.

Brower, J. E. and J. H. Zar.1997. Field and Laboratory Method for GeneralEcologyWm.C. Brown Company Publisher,America.301hal.

Eleftheriou, A. And A. Mcintyre. 2005. Methods for the Study of Marine Benthos. Blackwell Science, Oxford.Lannan,J.O.G. 1986. Priciples and Practices of Pound Aquaculture. Oregon State University. Press. USA

Gofredo, S. and N. E. Chadwick-Furman. 2000. Abundance and distribution of mushroom corals (Scleractinia: Fungiidae) on a coral reef at Eilat, Northern Red Sea. Bulletin Of Marine Science 6(1):241-254.

Hoeksema, B. W. 2012. Distribution patterns of mushroom corals (scleractinia: fungiidae) across the Spermonde Shelf, South Sulawesi. The Raffles Bulletin Of Zoology 60(1): 183-212.

Hermanto, B. 2013a. Keanekaragaman karang jamur (fungiidae) di perairan pulau Siladen , Minahasa Utara. Jurnal Ilmiah Platax 1(4):158166.

Hill J. dan Wilkinson C. (2004). Methods for Ecological Monitoring of Coral Reefs. Australian Institute of Marine Science, Townsville, Australia. 123 hal

Kramarsky, E., W, dan Loya, Y. 1996. Regeneration versus budding in fungiid corals. Marine Ecology Progress Series Vol. 134: 179185.

Mampuk, F., H. Tioho dan J. D. Kusen. 2013. Distribusi vertikal dan kepadatan karang fungiidae di Perairan Malalayang. Jurnal Pesisir dan Laut Tropis 1(1):42-47.

Nugraha, WA Munasik Witjadmoko. W 2004. Distribusi dan Struktur Populasi Karang Soliter Fungia Fungites di Pulau Burung, Pulau Cemara Kecil dan Pulau Menjangan Kecil (Kepulauan Karimunjaya) Jurnal Ilmu Kelautan. September 2004. Vol. 9(3):174-179.

Norsstrom, A.V., J, Lokrantz , M, Nistrom, H. T, Yap, 2006. Influence of dead coral substrate morphology on patterns of juvenile coral distribution. Marine Biology $150: 1145-1152$
Nybakken JW. 1992. Biologi laut suatu pendekatan ekologis. Terjemahan oleh Eidman, M., D. G. Bengen, Koesoebiono, M. Hutomo dan Sukristijono. PT. Gramedia. Jakarta. $459 \mathrm{~h}$.

Reid, C., Marshall, J., Logan, D., dan Kleine, D. 2011. Terumbu Karang dan Perubahan Iklim. Coral Watch, The University of Queenslan, Australia 272 Hlm.

SADARUN 1999. Transplantasi Karang Batu (Stony Coral) di Kepulauan Seribu Teluk Jakarta. M.Sc Thesis pada Program Pasca Sarjana Institut Pertanian Bogor. 67 pp

Sadarun, Baru. 2008. Pedoman Pelaksanaan Transplantasi Karang. Satker Direktorat Konservasi dan Taman Nasional Laut. Direktorat Jendral Kelautan Pesisir dan Pulau-pulau Kecil Departemen Kelautan dan Perikanan Jakarta.

Soegianto. 1994. Ekologi Kuantitatif Metode Analisis Populasi dan Komunitas. Airlangga University - Press. Surabaya.

Suharsono,1996. Jenis-jenis Karang yang Umum dijumpai di Perairan Indonesia. Pusat Penelitian dan Pengembangan Oseanologi Lembaga Ilmu Pengetahuan Indonesia, Jakarta

Suharsono. 2008. Jenis-jenis karang di Indonesia. Pusat Penelitian Oseanografi, Lembaga Ilmu Pengetahuan Indonesia. COREMAP PROGRAM, Jakarta. 372 pp.a

Suharsono. 2010. Jenis-Jenis Karang Di Indonesia. Lembaga Ilmu Pengetahuan Indonesia. COREMAP PROGRAM, Jakarta. 372 hal.

Sukarno, M. Hutomo, M. K. Moosa dan P. Darsono. 1981. Terumbu karang di Indonesia. sumberdaya, permasalahan dan pengelolaannya. Proyek Penelitian Potensi Sumberdaya Alam Indonesia. Lembaga Oseanologi Nasional, Lembaga Ilmu Pengetahuan Indonesia, Jakarta. 112 pp.

Supriharyono. 2007. Pengelolaan Ekosistem Terumbu Karang. Penerbit Djambatan. Jakarta. X+129 p.

Thamrin. 2006. Karang: Biologi Reproduksi \& Ekologi.Minamandiri Pres. Pekanbaru.

Veron J.E.N., L.M, Devantier., E. Turak., A.L. Green., S. Kininmonth., M. 
Stafford-Smith and N. Peterson. 2000. Delineating the coral triangle. Galaxea, Journal of Coral Reef Studies. 11 : 91100.

Veron, J.E.N \& M. Stafford-Smith, M. 2010, An Electronic Key to The Scleractinian Corals of The World Conservation Internasional. Australian Institute of Marine Science. Great Barrier Reef Research Foundation. Australia. 